\title{
Underlying Aspects in Tagore's Translation Of Red Oleanders: A Critical Reading
}

\author{
Sharifuzzaman (Corresponding author) \\ Jashore University of Science and Technology, Bangladesh \\ Email: sharifsazal444@gmail.com
}

Received: 20/02/2021

Accepted: 02/05/2021

Published: 01/07/2021

Volume: 2 Issue: 4

How to cite this paper: Sharifuzzaman.(2021). Underlying Aspects in Tagore's Translation of Red Oleanders: A Critical Reading. Journal of Critical Studies in Language and Literature, 2(4), 20-26

DOI: https://doi.org/10.46809/jcsll.v2i4.74

Copyright (C) 2020 by author(s) and Global Talent Academy Ltd. This work is licensed under the Creative Commons Attribution International License (CC BY 4.0).

http://creativecommons.org/licenses/by/4.0/

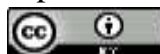

\begin{abstract}
Though Rabindranath Tagore's works have been studied and praised for decades around the world, his struggles to reconcile cultural as well as linguistic differences between English and his native tongue, Bengali through translations of his works have largely been overlooked. This paper though a comparative study between Tagore's drama Raktakarabi and its translated version Red Oleanders, seeks to find out how Tagore deals with various cultural, literary and linguistic issues that have arisen during the translation and whether the differences between two languages with distinct natures and unique histories have forced him to make fundamental changes to the play. The research also aims to critically look at the reasons behind Red Oleanders' apparent failure in the west and takes into account relevant translation theories to discuss how various changes to the play have contributed to creating stark contrasts between the original and the translation.
\end{abstract}

Keywords: Raktakarabi, Red Oleanders, Translation, Tagore, Cultural Differences, Linguistic Barrier, Colonial Literature

\section{Introduction}

Translated literary works, throughout human history, have been subject to criticisms on account of their nature. A translation could be done in numerous ways and therefore could easily lose the essence of the original. A translator may faithfully convert a text from one language to another, word for word, and yet could lose the most important themes embedded in the original. He may try to capture the sense of the original by veering off the path of literal translation and in the end, may find himself to be so far away from his designated path that rather than a translation, he may feel he has created something entirely foreign. And these problems and dilemmas have come to the forefront in Tagore's translated drama Red Oleanders.

Translated literary works, throughout human history, have been subject to criticisms on account of their nature. A translation could be done in numerous ways and therefore could easily lose the essence of the original. A translator may faithfully convert a text from one language to another, word for word, and yet could lose the most important themes embedded in the original. He may try to capture the sense of the original by veering off the path of literal translation and in the end, may find himself to be so far away from his designated path that rather than a translation, he may feel he has created something entirely foreign. And these problems and dilemmas have come to the forefront in Tagore's translated drama Red Oleanders. 
Rabindranath Tagore, the legendary Indian Nobel prize winning author, found himself in a fix on his journey to translate his much adored drama Raktakarabi into English. An ethnic Bengali, Tagore has always used allegories, allusions and metaphors (exclusive to Bengali) in his carefully constructed literary pieces which would be quite impossible to directly convert into another language that doesn't share any cultural, religious or sociological links with his native tongue. Originally written in 1923-24, Raktakarabi was first published in a Bengali journal named Prabasi in 1924. Later that same year, its English-translated version (done so by Tagore himself), Red Oleanders appeared in Vishva-Bharati Quarterly.It was reprinted again in 1926.

Though the original was received with praises and critical acclamation for its depiction of a dystopian materialistic society as well as its representation of an ever-raging battle between 'man and machine', the translated work had an extremely hard time convincing its western audience. One researcher Basudeb Chakrabarty elaborates this point citing Ananda Lal's "Rabindranath Tagore Three Plays" and shows that Red Oleanders was received quite poorly in the west. (Chakravarty, 2010, p. 519). In his book, Ananda Lal mentioned how western reviewers reacted to the play. The Times Supplement in July of 1925 made the following scathing remarks,

Tagore seems to depend on the very vagueness of his style for whatever meaning the drama can support. For the greater part of the time, it is quite impossible to discover what is happening... There is not the faintest attempt to present the few scattered and mysterious events in a logical sequence... The characters of the play are sufficiently lifeless to compel one to wonder what intellectual or moral purpose they can possibly serve...The most acute of Tagore's literary failings is perhaps a rather unbridled passion for metaphor. In Red Oleanders, the profusion of metaphor is particularly trying... Tagore has been far more occupied with words that it is the business either of the dramatist or the poet to be. (Lal, 1987, pp. 72-73)

Similar or even harsher indictments of his work could be seen in other western outlets as well. The Dublin Evening (1925), The Saturday Review of Literature (1926) and many others echoed a similar tone. Literary critic Edward Thompson, in his book Rabindranath Tagore: Poet and Dramatist (1926), dismissed the play accusing it of having no impression at all. The Sheffield Telegraph in July 1926 had this to say about the play,

Mr. Tagore is too serious a writer to be suspected of publishing absolute nonsense on purpose. So one must suppose he did it by accident. Presumable he is able to follow the workings of his brain, and it would be very interesting to hear him just what it is all about. (Aronson, 1978, p. 84)

A shocked Rabindranath hit back at his western critics in his piece published in October 1925 edition of Vishva-Bharati Quarterly saying,

Some few criticisms of my Red Oleanders that have appeared in the English papers have convinced me that, to a considerable portion of my readers in England, this play of mine seems obscure in meaning. Such a fact, I believe, usually comes as a surprise to an author, because generally a work of this nature springs from the vision that is vivid to himself and the feeling that belongs to his direct experience. (Tagore, Red Oleanders: Author's Interpretation, 1925, p. 283)

The veteran author goes on to say, since Red Oleanders is a 'mere translation', it may not occupy the same place (as its original has) as literature in a language which is not the author's own. But nonetheless, he assures, the play has a meaning which "legitimately claims literary expression". (Tagore, Red Oleanders: Author's Interpretation, 1925, p. 283)

A few researchers have tried to get to the bottom of this problem which revolves around the contradictory responses Tagore got from different versions of the same play. Many have attributed the western criticisms to the fact that Rabindranath may have been viewed by a significant number of westerners as an Indian nationalist and Congress sympathizer, a view that was only strengthened after his decision to renounce the Knighthood conferred by the British Empire after Jallianwala Bagh Massacre of 1919. Apart from colonial considerations, Tagore's supposed closeness to German intelligentsia also might have played a part into all this. But the fact the Red Oleander still remains unrecognized in the west to this day (so long after the liquidation of the British Empire in India) even by unprejudiced minds in the west begs the question, which elements of Raktakarabi got stripped in Red Oleanders while being translated to invite such reactions and also, how exactly did Tagore deal with various issues to convert his play into English?

Few researchers have attributed the failure of Red Oleanders to the apparent "communication gap" between the original and the translation. According to them, since Bengali and English are vastly different languages with long and distinct pasts, many metaphors and allegories along with subtle references recognizable only by Bengalis (or someone who understands the culture) simply got lost. Basudeb Chakrabarty, citing western criticisms on the play, commented that,"Western reviewers did not understand Tagore's Red Oleanders because they knew nothing about the cultural significance of the linguistic framework of the Bengali language.” (Chakravarty, 2010, p. 521)

It is therefore necessary to examine and do a comparative study between the original and the translated text to get a better grip on the issue.

This research piece would use the texts of Raktakarabi (2016 Edition from Suchayani Publishers), the original Bengali version of the drama, and the English translation, Red Oleanders (1948 Edition from Macmillan and Co. Limited), as principle literature. Other works used in this research will include various research papers on the issue along with the book Translation Studies ( $4^{\text {th }}$ Edition) by Jeremy Munday.

Moreover, the paper would employ the qualitative method in its approach and use the APA format while citing other works and papers relevant to the discussion. 


\section{Research Questions and Objectives}

This research article seeks to answer the following questions:

1. What are the issues Tagore faced during the translation and how did he deal with them?

2. How did the author shrink the cultural as well as other gaps between Bengali and English to represent cultural, religious and metaphorical assertions which are exclusive to Bengali?

3. Did Tagore's employed tactics significantly alter any part of the play?

The objectives of this paper include finding out how the various cultural, religious as well as other differences between the languages have been dealt with. Since studies into this particular area of Tagore's works have always been in short supply, this paper would seek to provide a new outlook in the matter. Basudeb Chakravarty in his paper "The Unrecognized Work of Tagore as Translator: An Assessment" argues that though the originals have received tremendous attention for years, Tagore's translated works haven't been studied closely and systematically either in India or abroad which includes Raktakarabi.

\section{Tagore and Translation Methods}

Debate regarding translation methods has been going on for centuries. Since the days of Roman politician Cicero in 46BCE, different approaches for translation of texts and speeches from one language to another have been debated and it has carried on well into our time. The principle point of these arguments has mostly revolved around the distinction between 'word for word' and 'sense for sense' translation methods. Jeremy Munday in his book Introducing Translation Studies has cited linguist George Steiner who in 1998 described the translation debate to be a 'sterile' one over the 'triadic model' of 'literalism','paraphrase' and 'free imitation'. In that discussion the famous English poet and translator John Dryden is also featured who categorizes all translations into three distinct groups:

1. Metaphrase: This category refers to that particular type of translation which seeks to go for 'word for word' translation and concentrates on the literal aspect of the text rather than the essence or meaning.

2. Paraphrase: This type has been described as less concerned with the literal meaning of every word and instead, seeks to bring the 'sense' out while translating but at the same time never really veers too far away from the original.

3. Imitation: This category is generally called the 'free translation' mode and it usually refers to a 'type of adaptation' that a translator may create from the original. It doesn't concern itself with either the original's form or meaning in any strict sense.

Tagore hasn't tried to rigidly follow any of the categories, rather in Red Oleander he tries to combine the methods of 'Paraphrasing' and 'Metaphrasing' to provide the readers with what he believes is the true essence of Raktakarabi.

Apart from the classifications, writers and linguists have also tried to set out rules for translators to follow in order to have a 'good translation' like Etienne Dolet who talked about 5 principles in 1540,

A. The translator must perfectly understand the sense and material of the original author, although he should feel free to clarify obscurities.

B. The translator should have a perfect knowledge of both SL (Source Language) and TL (Target Language), so as not to lessen the majesty of the language.

C. The translator should avoid word-for-word renderings.

D. The translator should avoid Latinate and unusual form.

E. The translator should avoid assemble and liaise words eloquently to avoid clumsiness. (Munday, 2016, p. 45)

If one compares all of the abovementioned requirements with Tagore and his translations, he/she would be surprised to find out how well Rabindranath Tagore had embodied all those qualities. It's even more interesting when we consider the fact that Tagore may have never studied 'Translation theories' as they were not quite developed (most being not available at all) in his time.

Tagore certainly had mastery over Bengali and English, and in the case of Raktakarabi he was the original author as well as the translator, therefore having perfect idea of what the original text intended to convey. Therefore, he was in the most privileged position to translate the play.

In the translation, we find that Tagore avoids, to the best of his abilities, the use of archaic and unusual words. Words used in Red Oleanders are mostly day to day English words which couldn't have been clearer in their meanings. He also avoids word-for-word renderings wherever necessary (as in wherever word-for-word seems unusual or unnatural, he goes for traditional English sentences). For example, in Raktakarabi, the cave digger Phagulal while searching for his liquor during a holiday tells his wife Chandra something which in 'literal sense' would be,"Where have you hidden my liquor Chandra, Get it out." (Tagore, 2016, p. 14)

Instead he simply uses "My bottle Chandra? Out with it" (Tagore, 1948, p. 34), which is an easier and a more natural expression. Couple of lines later, Phagulal mentions the occasion of the holiday where he says something that if translated word-for-word would go like this, "It is holiday today. Yesterday was the fast day of Ma Ranachandi. Today's the puja (veneration/worship) of flag and weapons."

Instead Tagore goes with this line, "Isn't it our holiday? Yesterday was the fast day of the War Goddess. To-day they worship the flag." (Tagore, Red Oleanders, 1948, p. 34). The translator in Tagore here simply avoids going into religious jargon since the lore regarding Devi (Goddess) Chandi or Ranachandi might be completely unfamiliar to English speakers. 
He therefore just uses the term 'War Goddess' which is easily comprehensible and cuts out part of the dialogue that doesn't quite sound as good as it does in Bengali.

But what's more interesting is Tagore completely cuts the next two lines in the English translation where Phagulal talks about how the authority in Yaksha town keeps their armory, liquor storage and temple close to each other. It might be for the simple reason that the translated form could just sound out of place and unnatural unlike the Bengali version. Therefore Tagore's approach and efforts should be acknowledged in trying to create a drama similar in essence to Raktakarabi but different in structure (for the sake of creating a natural structure for English speakers).

Jeremy Munday in his book cites Friedrich Schleiermacher to discuss similar aspects of translation. He says, Although it may seem impossible to translate scholarly and artistic texts, since the ST(Source Text) is couched in language that is very culture-bound and to which the TL (Target Language) can never fully correspond, the real question, according to Schleiermacher, is how to bring the ST(Source Text) writer and TT (Target Text) reader together. He moves beyond the strict issues of word-for-word and sense-for-sense, literal, faithful and free translation, and considers there to be only two paths open for the 'true' translator: "Either the translator leaves the writer in peace as much as possible and moves the reader toward him, or he leaves the reader in peace as much as possible and moves the wrtier toward him." -Schleiermacher 1813 (Munday, 2016, p. 48)

Tagore, in case of Raktakarabi, had the advantage of being the author and he, as the fluent English dialogues suggest, did move towards the readers. But the extensive use of symbolism and allegories used in the original drama dictated that he also had to bring his readers towards his side as well, even if for a few particular expressions which couldn't be possibly translated into 'natural' and comprehendible English sentences. And there may lie a reason that contributed to Red Oleander's failure, although it could be argued that as translator, Tagore simply didn't have a way to completely eradicate the cultural differences between the two languages (Bengali and English), especially in case of a complex and metaphorical play like Raktakarabi.

\section{Raktakarabi's Transformation into Red Oleanders}

\subsection{Names and Titles}

One of the most significant aspects of Raktakarabi is the names and titles used in the play. Like many other works of Tagore, Raktakarabi has important significance in its title. During its composition in 1923, Tagore contemplated using titles as "Jakkhapuri" or "Nandini". But eventually he settled for Raktakarabi for the simple reason that it captures the theme of the play the best. Raktakarabi's blood red color reminds us of revolution and love, both of which are central themes of the play. Therefore, to convey the same meaning, Tagore translated the name to English making the translated work's title Red Oleanders.

'Red Oleanders' however fails to capture the complete dimension of emotions that 'Raktakarabi' evoke. "Rakta" literally means "blood" in Bengali and together with "Karabi"(which points towards a particular type of flowers that's both beautiful and poisonous), it conveys an extremely powerful meaning. It reminds someone of revolution, struggle, love and sacrifice which are not quite that vivid in the title 'Red Oleanders'. Nonetheless, physical use of Red Oleanders by the protagonist does convey a fair amount of rhetoric and symbolism once the play gets going.

But Tagore refuses to change the names of the characters who all have names that are extremely allegorical. Nandini, the female protagonist, wearing a garland of red oleanders, preaches the philosophy of life, significance of natural beauty and brings about a revolution in a dystopian society. Her name literally means 'something pleasing' or 'someone beautiful'; the name of her one true love, Ranjan, also has a similar lexical meaning. Nandini and Ranjan both are similar to each other yet so different. Both have revolutionary nature and they are 'full of life' but at the same time, Nandini is the symbol of love and compassion while Ranjan is rebellious and defiant. Their names are brilliantly connected to their nature.

The cave digger kid Kishore has an interesting name as well. It literally means "adolescent or youth" in Bengali and his refreshing dialogues along with his selfless nature provide a beautiful insight into his innocent mind.

Same is true for the name of the city as well. The dark dystopian setting of the play is a place called Jakkhapuri in Raktakarabi which is translated into English as Yaksha Town. Jakkhapuri refers to a place where one would find Jakkho (treasures buried deep within the earth), it may even refer to Underworld. The name sends a chill down the audience's spines but the translated name "Yaksha Town" does not invoke a similar emotion, thus making Red Oleanders quite different from Raktakarabi right from the beginning.

Rabindranath Tagore's decision to not change the names is quite interesting. It seems, he sought to bring the readers closer to the original writing for certain portions of the play to keep the original symbolism and allegories, rather than the opposite, something that agrees with one of Schleiermacher's perceptions of translation. The original names, in their unchanged form, could steer Red Oleanders towards the original's path but at the same time did bear the risk of ending up as an insignificant play to those who are not familiar with the names beforehand.

4.2. Allegories and Allusions

Allegories, symbols, metaphors and allusions are the components that give the play its core. They are everywhere and they bear significant importance in Raktakarabi. The natures of the characters too are allegories of the natural world and the characteristics of the seasons. Researcher Basudeb Chakravarty laments the western criticisms of the play because he feels many simply didn't get the drama, 
...Could they feel the subtle influence of the Bengali seasons represented through the characters of the play? Could they distinguish between autumn and the late autumn which are known as 'Hemanta' in Bengal? If Kishore represents autumn, then Bishu represents 'Hemanta' and the Professor represents winter. Nandini is the eternal spring. (Chakravarty, 2010, p. 521)

Another example of these complexities can be found during the first conversation between the Professor and Nandini where Nadini asks the Professor why she should fear Jakkhapuri (Yaksha Town) to which the Professor gives a metaphorical reply. Its literal translation would be,“...It's a city under eclipse,Rahu in the Gold caves has eaten into it. He is not whole himself and he won't allow anyone else to remain so." (Tagore, 2016, p. 8)

Tagore uses the name of mythical Asura(Demon) Rahu here who as the legend tells us sought to drink the elixir of immortality through deception. The demon was cut into two by an avatar of God Vishnu but since the elixir already made the demon immortal, his head and body (now named Rahu and Ketu) were forever cursed to roam the skies. According to the Hindu Mythology, Rahu seeks to swallow the sun and the moon occasionally (as they pointed him out to Vishnu) when the eclipses happen ,but then whatever Rahu eats eventually comes out of the other end since he doesn't have a body. It's a mythological story and a metaphor for the dystopian man made hell of Jakkhapuri or Yaksha town which is not whole itself, and doesn't let anyone else to be so. Men mine gold from the depth of the city making both the city and enslaved workers incomplete -it's a great representation but Tagore, it seems, decided to forsake it for the simple reason that this allegory won't mean anything (or might even sound absurd) to English speakers. He therefore, uses the following line,"...The shadow demon who lives in the gold caves has eaten into it. It is not whole itself, neither does it allow anyone else to remain whole." (Tagore, 1948, p. 12)

It's elegant and easy, yet doesn't have the same mystery and myth behind it. Also Tagore refers to the Demon as 'who' in the first portion, yet the pronoun in next part of the sentence says "It", which might mean that in the translated version Tagore meant to tell that since the city isn't whole, it doesn't let others to be so whereas in the original version, Rahu the 'Asura' (who could be the symbol for greed) ate into the city stripping both the city and the workers of their complete selves.

Another example of this is the mention of 'blue-throats' in Red Oleanders. A pair of birds helps Nandini determine when she would be able to meet Ranjan and bring the reign of the evil King and his minions to an end. It's obviously a simple metaphor through which the author conveys a familiar plot, how nature helps Nandini restore life in the city, how mankind and nature must always help each other to survive.

But Raktakarabi's version of the 'blue-throats' are called 'Nilkantha' which Tagore mentions as a footnote in Red Oleanders for any interested party as that particular name bears a lot of significance rather than just be a representation of nature. Nilkantha is the name of the mythical god Shiva. He is part of the Trinity along with Brahma and Vishnu, and known as 'The Destroyer'.

At the final portion of the play, Nandini places a feather of the 'blue-throat' birds on Ranjan's crest and Ranjan's death triggers a revolution which destroys the city's rigid and powerful structure while at the same time, makes the King himself join the revolution against the monstrous structure of 'Jakkhapuri' tearing up the flags.

Tagore dealt with the problem of translating 'Nilkantha' in a different way compared to his earlier approaches. He knew he had to translate the Bengali word into English for the foreign audience to understand, at the same time he added a footnote in what I interpret as a hope that it might just lead a few readers to discover what that word's significance really is. In all fairness, Tagore or for that matter, any translator would fail to convey the entire meaning of a one scene complex play like Raktakarabi through translation successfully. Nonetheless Tagore tries and the fact that the play still remains somewhat close to Raktakarabi is his success, although it also highlights the insurmountable cultural barrier between the languages which at least in some cases makes it quite impossible to 'just convert the events into another medium', no matter how hard one tries.

\subsection{Tagore's Treatment of Songs and Compositions}

Tagore's songs and poems have been praised as his best works by many. His translation skills have been praised in the East as well as the West in the early years. "Song Offerings" (Tagore's translated version of the original volume of poems named Gitanjali) won the Nobel Prize in 1913. Subsequently he translated a few more of his volumes which got praises as well. In this aspect, one researcher points out an important point,

The interesting point in Rabindranath's case-his own translation of poems written by himself in Bengali-is that the self that he was presenting to the other was in a large sense a creation of the other. The mystic or spiritual Indian was a familiar sphere in which the colonizer could accommodate a native; this self, which Rabindranath presented in his English versions was a constituted subject which conform to the boundaries of the discourse that legitimized the native within certain permitted areas... The problem becomes apparent when Rabindranath started translating varied kinds of poems not of a specially devotional or spiritual kind. (Sengupta, 1990, p. 117)

So prejudice and colonial concerns may have played a part, as it has been described earlier, in undermining the latter translated works of Tagore. Nonetheless, if we closely look at the songs which are featured in Red Oleanders, we can see that Tagore has sacrificed parts of his original songs to make the translation more natural.

Bishu, the carefree singer, sings the following lines at one part,

"Boatman of my dreams,

The sail is filled with a boisterous breeze

And my mad heart sings

To the lilt of the rocking of thy boat, 
At the call of the far away landing." (Tagore, 1948, p. 37)

This particular song, though can't be regarded as a word-for-word translation, is surprisingly close to the original in theme and structure. Interestingly Tagore drops the next stanza completely, perhaps because of the simple reason that it could potentially alter the structure of the entire song. The Bengali version of the song basically follows the rhyming scheme $\mathrm{ABBAAB}-\mathrm{CCDDA}$ while the translated version simply covers the first stanza ABABC (with incredible precision in the meaning) and ignores the second one.

This particular maneuver does not harm the meaning of the overall text much, instead Tagore here actually saves the natural and rhythmic nature of the song which is extremely important to convey what the character Bishu seeks to do so. For a free spirit like Bishu who wants to inject life into whatever he runs into, a boring, long, unrhythmic monologue could be more harmful than the loss of a stanza.

Subhas Chandra Dasgupta in his paper "Rabindranath Tagore and Translation Studies" describes how the concept of 'loss and gain' (of meaning and words) in translation vexed Tagore. He presents Tagore's letter to Rothenstein (dated 7 June 1912) where Tagore writes, "I send you some more of my poems rendered into English...I know you will understand them through their faded meanings" (Dasgupta, p. 11).Dasgupta concludes,

Since translation loss is inevitable, the translator makes use of his creative freedom to compensate it by rendering the original in keeping with his vision of life or the aesthetic, cultural and linguistic needs of the target readers. In his discussions of translation Tagore has time and again emphasized the creative power of a translator for the success of translation. (Dasgupta, p. 11)

Therefore, Tagore has sought to use his creative skills to convey what he considers the most important part of a composition, be it a poem or a song embedded in a play. It's that reason which leads him to translate songs used in Raktakarabi in a particular manner which would, in his opinion, have similar impact in Red Oleanders.

Similar tactics utilized by Tagore have been recognized by other researchers as well. Md Abu Zafar in his paper on Tagore's translation of poetry remarks,

Tagore's third book of translated poetry from his Bengali originals is The Crescent Moon (1913). This book contains translation of forty poems, most of which were selected from the original Sisu (1903), which Tagore wrote for children. In translating these poems Tagore hardly took any care to retain the essential literary qualities of the originals. MahaswetaSengupta comments that these translations 'lack the concrete sensuousness of the originals. And seem to be rather wordy...sentimental and ponderous'. (Zafar, 2013, p. 70)

Zafar then goes on to comment how Tagore keeping in mind the failure of The Crescent moon brought out Fruit Gathering (1916) where he assembled translations of poems from his famous volume known as The Balaka (1916). The researcher points out that,

The original Balaka poems are remarkably free in form and intellectually abstract in content. It is exceptionally difficult to retain these aspects of the original in translation. Of course Tagore did not include the more complex poems of the originals. (Zafar, 2013, p. 70)

It is quite clear that Tagore's preference of meaning and sense over words and content often dictated his actions. He would rather have that his compositions convey a similar meaning (to the original) rather than the exact content which may mean different things in different culture. That's why in Red Oleanders, he has repeatedly tried to present songs and in many cases dialogues in a way that sound more organic and natural,while at the same, has sought to create an atmosphere in Red Oleanderswhich was present in Raktakarabi. Therefore, he was ready to alter the texts in the translated version.

In the final portion of the play, the 'Song of Autumn' plays in the background as the curtain falls. The song expresses joy as the harvesting season enriches earth with 'ripe corns'. The name of the song itself could be cited to show Tagore's approach to translation. In the original Bengali version, it's called 'Song of Poush' since the month of Poush which marks the beginning of winter in Bengal is known to be the harvesting season. As this particular song is utilized here to convey the meaning how newly harvested crops fill up everyone with joy and hope, Tagore translates 'Poush' as 'Autumn' to draw a similar picture in the minds of his foreign readers who would be much familiar with the 'autumn harvesting season', something common in the west.

The translator (Tagore himself) here also goes for minor changes. Whereas the Bengali version simply refers to how the crops are filling the mantle of dust (Dhularachol), the translated one clarifies that it's the "Earth's mantle of dust" lest the readers should get confused (The Bengali term "Dhularachol" has certain connotations which are connected to mother Earth unlike the English phrase "mantle of dust").

4.4. Others Aspects

Tagore also had to face numerous occasions during his translation of Raktakarabi where he had to decide whether he should keep the original references, and since many of those references, allusions, metaphors are exclusive to Indian culture (Bengali culture, to be more specific), keeping the original expressions often bore the risk of confusing the audience.

It seems, in many cases, Tagore couldn't bring himself to completely change the original references. For example, when the preacher Gosain talks of the cave diggers he compares them to 'Kurma avatar' which is a reference to God Vishnu who in form of a giant tortoise supported in his back the mythical churning stick to help the gods retrieve treasures dissolved in the 'Ocean of Milk'. Tagore, knowing the lack of knowledge of most English speakers in Hindu scriptures, sought to solve the problem by simply comparing the diggers to a giant tortoise that held up the sinking earth providing a similar (though diminished) meaning to the original. 
In other cases, Tagore has made more fundamental changes. He has translated Ashar-Chaturdashi (14 ${ }^{\text {th }}$ day of Ashar which is a month in Bengali calendar that together with the month of 'Srabon' makes up the rainy season) to '14 " day of the moon in rainy June' which is understandable given the context. But what's mysterious is how he translates the line "Loha khoye geche" which refers to something like 'iron has decayed' (Tagore, Raktakarabi, 2016, p. 36). That particular part of dialogue is represented in Red Oleanders through the following line,

'...the steel is eaten away' (Tagore, 1948, p. 110)

Though it is unclear why he would make such a change in translation that has little cultural or semantic significance, it could be Tagore's artistic sense that led him to believe 'steel' would sound better in the translated version.

A few other instances where the translation feels a bit out of place could have similar reasons behind them. One such instance has been described by Basudeb Chakravarty in his paper in the following manner,

The peculiarities of those English expressions in Red Oleanders were perhaps due to Tagore's mother-tongue interference in transferring connotations of certain lexical items like 'Parasmani' into English (It should be philosopher's stone but Tagore translated it into Touchstone which is actually a real stone black jaster with the help of which the jewelers examine the 'purity of gold'). (Chakravarty, 2010, p. 517).

\section{Conclusion}

The famous linguist George Steiner once remarked, "When a language dies, a way of understanding the world dies with it." It's a deep and insightful way of how one can view a language - a way of seeing the world.

For two distinct languages like English and Bengali with their long and distinct cultural as well as literary histories (not to mention, unique social and religious backgrounds), it's almost impossible to completely reconcile all the differences. Rabindranath Tagore, who was and remains to be the biggest name in Bengali literature, in his attempt to translate Raktakarabihas tried to bring together all the important aspects of the original play and build a structure which seeks to be a literary composition for the English readers while at the same time retains the revolutionary nature of Raktakarabi at its core. $\mathrm{He}$ is to be congratulated for his incredible translation skills, which as we have seen remains perfectly in sync with the theories and principles of linguists and experts in the field of Translation Studies. But we can eventually see that Raktakarabi has too much contextual references, lore, allegories as well as symbolism that identifies with the Bengal culture (or in a broad sense Indian culture) that in the end the translated piece Red Oleanders couldn't quite convey the same emotions and messages which Raktakarabi could.

Tagore has, as we have discussed, gone far to preserve the essential elements of Raktakarabi in their original form while trying to convert the play into English. Ironically, this conservatism itself has fundamentally changed the play in many ways as ingenious and brilliant Bengali expressions have been transformed into lifeless English vocables. The veteran author turned translator has used 'paraphrasing' as well as 'word-for-word translation' in places and changed the dialogues significantly where he felt necessary but nonetheless Red Oleanders to its audience has, in the end, turned into something alien in its meaning, if not in its form as well.

Tagore's efforts to bring Jakkhapuri's (Yaksha Town) inhabitants into the English speaking world have cost the play its core essence. Its playful expressions, terrifying and mythical allegories and foreshadowing have remained Bengali even after their transformation into English rendering it obscure and confusing to those unfamiliar with the contexts which explains the contradictory responses the play received at home and abroad. Therefore, in the end Red Oleander's apparent failure might just be that it is an English drama where all the important aspects are unrecognizable to most English speaking people. It is the towering symbol of Tagore's translation skills while at the same time, a reminder of how cultural as well as linguistic barriers present between two languages can create a irreconcilable schism between a composition and its translation.

\section{References}

Aronson, A. (1978). Rabindranath through Western Eyes. Calcutta: Riddhi-India.

Chakravarty, B. (2010). The Unrecognized Work of Tagore as Translator: An assessment of Red Oleanders. Rupkatha Journal of Interdisciplinary Studies in Humanities (ISSN 0975-2935), 2(4), 513-528.

Dasgupta, S. C. (n.d.). Rabindranath Tagore and Translation Studies. Retrieved from Academia.edu: https://www.academia.edu/43376316/RABINDRANATH_TAGORE_AND_TRANSLATION_STUDIES

Lal, A. (1987). Rabindranath Tagore Three Plays. Calcutta: M.P. Birla Foundation.

Munday, J. (2016). Introducing Tranlation Studies. Rouledge.

Sengupta, M. (1990). Colonial Poetics: Rabindranath Tagore in Two Worlds. Ph.D dissertation, University of Massachusetts.

Tagore, R. (2016). Raktakarabi. Suchayani Publishers.

Tagore, R. (1948). Red Oleanders. Macmillan and Co. Limited.

Tagore, R. (1925, October). Red Oleanders: Author's Interpretation. The Vishva-Bharati Quarterly, pp. 283-286.

Zafar, M. A. (2013). Tagore's Poetry in English Translation: A Critical Review. Journal of the Asiatic Society of Bangladesh (Hum.), 58(1), 67-82. 